\title{
The effect of anteroapical aneurysm plication on end-systolic three-dimensional strain in the sheep: A magnetic resonance imaging tagging study
}

Julius M. Guccione, $\mathrm{PhD},{ }^{\mathrm{a}, \mathrm{b}}$ Joseph C. Walker, $\mathrm{PhD}{ }^{\mathrm{c}}$ Jeremy R. Beitler, BS, ${ }^{\mathrm{b}}$ Scott M. Moonly, $\mathrm{PhD},{ }^{\mathrm{c}}$ Peng Zhang, MD, PhD, ${ }^{b}$ Michael A. Guttman, MS, ${ }^{d}$ Cengizhan Ozturk, MD, PhD, ${ }^{d}$ Elliot R. McVeigh, PhD, ${ }^{d}$ Arthur W. Wallace, MD, PhD, ${ }^{b, e}$ David A. Saloner, PhD, ${ }^{b, f}$ and Mark B. Ratcliffe, MD

Supplemental material is available online.
From the Departments of Surgery, ${ }^{\mathrm{a}}$ Bioengineering, ${ }^{\mathrm{c}}$ Anesthesia, ${ }^{\mathrm{e}}$ and Radiology, ${ }^{\mathrm{f}}$ University of California, San Francisco, the Department of Veterans Affairs Medical Center, ${ }^{\mathrm{b}}$ San Francisco, Calif, and the Laboratory of Cardiac Energetics, ${ }^{\mathrm{d}}$ National Institutes of Health-National Heart Lung and Blood Institute, Bethesda, Md.

This study was supported by National Institutes of Health grant R01-HL58759 (Dr Guccione), Veterans Administration Merit Review (Dr Wallace), R01-HL-63348 (Dr Ratcliffe), and a predoctoral fellowship from the American Heart Association (Mr. Walker).

Received for publication Jan 20, 2005; revisions received July 11,2005 ; accepted for publication July 19, 2005.

Address for reprints: Julius M. Guccione, MD, Division of Surgical Services (112D), Department of Veterans Affairs Medical Center, 4150 Clement St, San Francisco, CA 94121 (E-mail: Julius.Guccione@med. va.gov).

J Thorac Cardiovasc Surg 2006;131:579-86

$0022-5223 / \$ 32.00$

Copyright $(92006$ by The American Association for Thoracic Surgery

doi:10.1016/j.jtcvs.2005.07.065
Objectives: Although repair of left ventricular aneurysm has been extensively studied, its effect on regional ventricular function remains unclear. The primary goal of this study was to quantify the effect of anteroapical aneurysm plication on systolic deformation in noninfarcted adjacent (border zone) and remote left ventricular regions in sheep.

Methods: Eight sheep underwent anteroapical myocardial infarction (25\% of left ventricular mass). Ten weeks later, animals underwent aneurysm plication. Two and 6 weeks after this operation, animals underwent magnetic resonance imaging with tissue tagging in multiple short-axis and long-axis slices. Fully 3-dimensional strain analyses were performed. All 6 end-systolic strain components were compared at midwall in the border zone of the aneurysm or repair and in regions $1 \mathrm{~cm}, 2 \mathrm{~cm}$, and $3 \mathrm{~cm}$ below the valves.

Results: Circumferential shortening progressively increases from before plication to 2 weeks after plication to 6 weeks after plication toward the border zone. The effect on circumferential shortening is most pronounced in the anterior wall and septum. The biggest change is from 2 to 6 weeks after plication (from $4.3 \%$ to $11.3 \%$ in anterior wall, $P<.0001$; from $3.5 \%$ to $6.5 \%$ in septum, $P<.0007$ ). Longitudinal shortening is decreased at 2 weeks after plication but then returns to baseline (with slight improvement in the border zone) at 6 weeks after plication.

Conclusions: Repair of left ventricular aneurysm significantly increases systolic circumferential shortening at the border zone in sheep.

$\mathrm{R}$ epair of left ventricular (LV) aneurysm has been extensively studied, especially its effect on global ventricular function. A previous study in our laboratory $^{1}$ suggested that aneurysm plication abruptly decreases LV volume and diastolic compliance, increases end-systolic elastance and stroke volume/end-diastolic volume (PRSW), but decreases the stroke volume/end-diastolic pressure (Starling) relationship. The net effect on global LV function was mixed. Furthermore, LV remodeling 6 weeks after aneurysm plication causes LV volume, end-systolic elastance, diastolic compliance, PRSW, and the Starling relationship to return to preplication values.

Savage and coworkers ${ }^{2}$ measured regional deformation in sheep after plication of anteroapical LV aneurysm using an array of sonomicrometry crystals. They found that aneurysm plication produced a shorter, more spherical ventricle and removed the dyskinetic segments but altered deformation in both circumferential and longitudinal directions. They believed the changes in ventricular wall geometry and deformation provide an explanation for the increased ventricular end-systolic elastance and unchanged stroke volume observed after aneurysm plication. 

Abbreviations and Acronyms
$\mathrm{ECG}=$ electrocardiographic
$\mathrm{LV}=$ left ventricular
$\mathrm{MR}=$ magnetic resonance
MRI = magnetic resonance imaging
PRSW $=$ preload recruitable stroke work

More recently, Kramer and coworkers ${ }^{3}$ measured regional deformation noninvasively in human subjects after aneurysm plication by magnetic resonance (MR) tagging. They concluded that LV aneurysm repair is associated with reverse remodeling and an improvement in the extent and orientation of intramyocardial function, especially at the middle and basal LV and inferior wall. However, their study and all previous MR tagging studies of LV aneurysm used only a 2-dimensional strain analysis in short-axis planes (transverse to the LV long axis). Thus, the effects of aneurysm plication on 3 of the 6 unique strain tensor components (ie, longitudinal normal strain and shear strains in the longitudinal-circumferential and longitudinal-radial planes) have not been quantified previously. Moreover, the accuracy of the other 3 strain tensor components (ie, circumferential and radial normal strain and shear strain in the circumferential-radial plane) is suspect when they are quantified without a fully 3 -dimensional strain analysis that also includes tagged long-axis MR images and, thus, takes into account through-short-axis-plane motion (which is significant, especially near the LV base).

In a typical MR tagging study, the black stripes or tags (signal voids) are "laid down" immediately after the scanner detects the R-wave or at end-diastole. End-systolic strain, for example, can be quantified after measuring the deformation of the tags from their undeformed end-diastolic configuration or state to their end-systolic state, which is easy to identify because it typically occurs when the equatorial LV circumference stops shrinking. The primary goal of this study was to quantify the effect of anteroapical aneurysm plication on end-systolic deformation in the border zone and remote LV regions in sheep. We hypothesize that repair of LV aneurysm significantly improves regional systolic function.

\section{Methods}

Animals used in this study were treated in compliance with the "Guide for the Care and Use of Laboratory Animals" prepared by the Institute of Laboratory Animal Resources, National Research Council, and published by the National Academy Press, revised 1996.

\section{Myocardial Infarction}

Castrated male Dorsett sheep were anesthetized (ketamine, 33 $\mathrm{mg} / \mathrm{kg}$ intramuscularly; isoflurane maintenance, $2 \%-4 \%$ inspired) and their lungs were mechanically ventilated (tidal volume 15 $\mathrm{mL} / \mathrm{kg}$; model 309-0612-800, Ohio Medical Products, Madison, Wis). During a left thoracotomy, snares were placed around the left anterior descending and second left anterior descending diagonal coronary arteries at a point $40 \%$ of the distance from the apex to the base. When present, branches of the posterior descending artery, which also perfused this region, were ligated $20 \%$ of the distance from the apex to the base. These coronary snares were sequentially tightened, causing an anteroapical infarction as previously described. ${ }^{4}$

\section{Aneurysm Plication}

Ten weeks after myocardial infarction, a partial lower sternotomy was performed with the sheep under general anesthesia. Pericardial adhesions were divided. Aneurysm plication was performed without cardiopulmonary bypass. The transition between infarcted aneurysm and uninfarcted myocardium was palpated and the LV aneurysm was plicated between two strips of Dacron felt. Polypropylene sutures (2-0 Prolene, MH needle; Ethicon, Inc, Somerville, $\mathrm{NJ})$ were passed through the felt, through and through the aneurysm at its border, and through the opposite strip of felt in a horizontal mattress fashion. The sternotomy was closed and the sheep was allowed to recover from anesthesia.

\section{Data Collection}

Non-ferromagnetic transducer-tipped pressure catheters (model SPC-320; Millar Instruments, Inc, Houston, Tex) were placed in the left and right ventricles with fluoroscopic guidance. Sheep were placed in a sealed plastic container and transported to the MR scanner. Each animal was positioned on its left side in the magnet (Siemens Symphony MRI scanner [1.5 tesla with Quantum gradients], Siemens Medical Systems, Iselin, NJ) with its chest centered in a Helmholtz coil. Tagged MR images in orthogonal short- and long-axis planes were obtained 10 weeks after infarction (before plication or before sham operation), 10 days after plication or sham operation, and 6 weeks after plication or sham operation. Propranolol $(0.1 \mathrm{mg} / \mathrm{kg}$, given intravenously) and atropine $(1.0 \mathrm{mg}$, given intravenously) were administered before data collection to decrease autonomic reflexes. All data were collected with the same level of anesthesia (1\% inspired isoflurane [Forane]).

\section{MRI}

A series of scout images was obtained to locate the heart and the true long- and short-axis planes. Subsequently, a set of 25 shortaxis imaging planes (6-mm thick) was obtained parallel to the true short-axis plane and at 5-mm intervals beginning at the level of the mitral valve and ending at a short-axis imaging plane that contained only apical myocardium and no LV or right ventricular endocardium. An additional set of 6 long-axis imaging planes was obtained according to the following criteria: (1) orthogonal to the true short-axis imaging plane, (2) intersecting the centroid of the $\mathrm{LV}$, and (3) oriented in a radial fashion with $30^{\circ}$ separations between long-axis imaging planes.

Image acquisition was synchronized to the $\mathrm{R}$ wave of the electrocardiographic (ECG) signal. During the actual image data acquisition, the ventilator (Hallowell 2000; Hallowell EMC, Pittsfield, Mass) was stopped for about 10 seconds at maximum inspiration (to minimize respiratory motion and the associated motion 
A

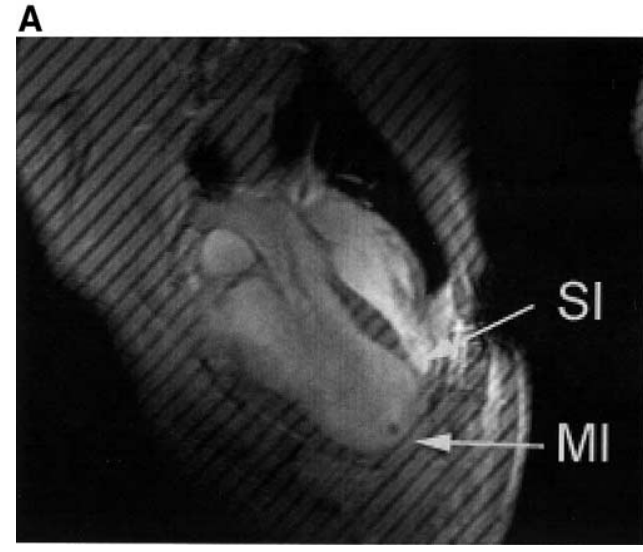

B

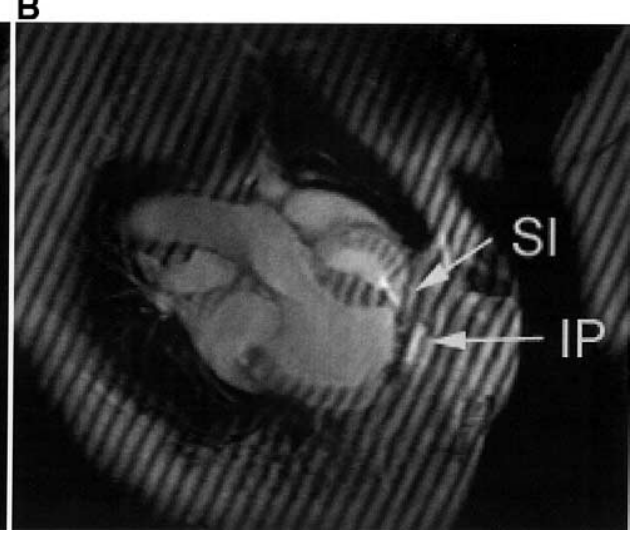

Figure 1. Long-axis MR images after myocardial infarction (A) and 10 days after plication (B) in sheep. MI, Dykinetic infarct; $S I$, septal infarct; $I P$, infarct plication.

artifacts in our MR images). During this time period, a series of images was acquired at 50-millisecond intervals until the approximate completion of the entire cardiac cycle. A segmented cine gradient echo sequence was used and the cardiac cycle was divided into 50-millisecond windows. Seven phase encoding lines were acquired in each window. Image data were collected over 16 heart cycles providing 99 phase encoding steps. The number of cardiac phases collected depended on the specific animal's R-R interval, with 10 cardiac phases being typical. The gradient echo sequence had an echo time of 4 milliseconds, an excitation angle $(\alpha)$ of $20^{\circ}$, and an acquisition matrix of $256 \times 102$. The field of view was set to $280 \times 230 \mathrm{~mm}^{2}$ and $280 \times 230 \mathrm{~mm}^{2}$ for the short- and long-axis images, respectively. Total MR study time was about 45 minutes. Raw data were interpolated to $256 \times 256$ pixel images, and these were transferred to a Silicon Graphics workstation (Silicon Graphics Inc, Mountain View, Calif) and were converted from Siemens format to SGI format using custom software (Figure 1).

\section{Data Analysis}

A slightly modified version of the MR tagging postprocessing software "Findtags" 5 (Laboratory of Cardiac Energetics, National Institutes of Health, Bethesda, Md) was used to contour the endocardial and epicardial surfaces and segment the tags in 8 to 12 images separated by 40 milliseconds for each imaging plane/slice that is fixed in space. The original number of contour points (64) in Findtags was quadrupled to account for the wide variation in LV wall thickness associated with LV aneurysm. To quantify myocardial deformation throughout the LV, we typically acquire these images in 6 different long-axis planes (at $30^{\circ}$ increments around the circumference) as well as in at least 5 different short-axis planes separated by $1 \mathrm{~cm}$ (Figure E1). Thus, each of our 3-dimensional MR tagging studies required the Findtags postprocessing of at least 88 to 132 images. Endocardial and epicardial contours are drawn by hand (using a computer mouse) in the initial (end-diastolic) image and created automatically by Findtags in subsequent images. Findtags is not perfect, however, so these automatically created contours sometimes need to be corrected by hand. Next, the 4-dimensional B-spline-based motion tracking technique for tagged MR images ${ }^{6}$ was used to compute all 6 unique, nonlinear, Lagrangian (Green's) strain tensor components referred to cardiac coordinates (ie, circumferential, longitudinal, and radial) at 36 locations (subendocardium, midwall, and subepicardium in each of 12 equally spaced sectors around the circumference) in each short-axis plane/slice (Figure E2) after correcting (with the postprocessed tagged long-axis MR images) for throughplane motion (Figure E3). It is important to note here that these strain values are based on the displacement of the entire tag lines and not only on the displacement of tag intersection points. The coverage of myocardium by tag lines shown in Figure E2 is typical. The endocardial contours at end-diastole and at endsystole were used to compute LV volumes at these time points. Each animal was placed on its left side with its chest in the same location within the MRI scanner. Moreover, each series of scout images used to locate the heart and the true long- and short-axis planes was obtained in exactly the same manner. These steps assured that each of the 12 sectors had the same anatomic location (eg, sector 8 corresponded to the middle of the anterior LV wall) in every animal and at every time point after the data analysis. We used distance of the short-axis imaging slice from the LV base at end-diastole to define the longitudinal position in our strain comparisons.

\section{Statistical Analysis}

All values are expressed as mean \pm standard deviation (SD) and compared by repeated-measures analysis using a mixed model to test for both fixed and random effects. We performed the analysis using SAS PROC MIXED (SAS System for Windows Version 9.1; SAS Institute, Inc, Cary, NC), which uses a maximum likelihood or restricted maximum likelihood estimation technique as opposed to ordinary least squares. As a consequence, subjects with missing data are not automatically deleted from the analysis. Also, variables can be either continuous or categorical and relationships between the variables can be linear or curvilinear since the mixed model does not assume a normal distribution. ${ }^{7}$ The statistical model was as follows: 


$$
\begin{aligned}
\mathrm{nn}, \text { Difference }= & \text { Time }+ \text { Distance }+ \text { Quadrant }+\mathrm{E}_{\mathrm{nn}, \text { Preoperative' }} \\
& + \text { LVVED }+ \text { LVPES }
\end{aligned}
$$

where Enn $=$ strain component, Difference $=$ difference between preoperative and postoperative values, Distance $=$ distance from the LV base, Quadrant = septum, anterior wall, etc, LVVED = volume at end-diastole, and LVPES = end-systolic pressure. As can be seen, the difference between pretreatment and posttreatment strain was used as the dependent variable, and absolute pretreatment strain was used as a covariate. ${ }^{8}$ Time, Distance and Quadrant cross terms were initially included, and statistically nonsignificant terms were sequentially removed beginning with those of highest order. The statistical significance of individual group comparisons was tested with the Student $t$ test. Thus, there were 16 regions (4 Quadrants at each of 4 Distances), each of which received a $t$ test. With 16 regions compared, multiplecomparison corrections would have made any statistical test a prohibitively high barrier. Therefore, to keep the statistical test as sensitive as possible, no multiple-comparison corrections were applied. Statistical significance was interpreted cautiously.

\section{Results}

Fourteen sheep began the plication protocol. Two sheep died at the time of myocardial infarction. Another 4 sheep either developed unusually small LV aneurysms (n $=2$ ) or yielded no MR images due to technical difficulties $(\mathrm{n}=2)$. Thus, 8 animals completed the entire protocol. However, preplication strain data are "missing" from 2 of these animals because of an MR imaging artifact in 1 case and inappropriate ECG gating (ie, tags laid down in mid-systole) in another. Moreover, 6-week postplication strain data are missing in another 2 of the 8 animals that completed the entire protocol owing to inappropriate ECG gating. In other words, 6 animals made it through with complete acquisition of data before plication, 8 animals made it through with complete acquisition of data 2 weeks after plication, and 6 animals made it through with complete acquisition of data 6 weeks after plication. Repeated-measures analysis of end-diastolic and end-systolic LV pressures and stroke volume found no significant difference before and after aneurysm plication (Table E1). Two weeks postoperatively, aneurysm plication had a significant effect on end-diastolic volume $(P<.0048)$, end-systolic volume $(P<.0020)$, and ejection fraction $(P<.0439)$. Six weeks postoperatively, aneurysm plication had a significant effect on end-systolic volume $(P<.0214)$. There was a trend toward redilation (Figure E4), yet there was no significant difference in end-diastolic volume $(P=.319)$ or end-systolic volume $(P=.285)$ between 2 and 6 weeks after plication.

Figure E5 shows the longitudinal variation in 5 endsystolic strain components before aneurysm plication. Specifically, mean circumferential shortening (Figure E5, A) within a short-axis slice is greatest and remarkably constant (at $-12.3 \% \pm 5.3 \%$ ) between the base and the equatorial region ( $2 \mathrm{~cm}$ below the base) and then decreases monotonically from $(-12.3 \% \pm 5.1 \%$ at $)$ the equator to $(-4.8 \% \pm 5.1 \%$ in) the border zone $(4 \mathrm{~cm}$ below the base). Mean longitudinal shortening (Figure E5, B) increases with distance from the base before reaching a maximum (of $-15.7 \% \pm 7.1 \%$ ) in the equatorial region and then decreases monotonically from the equator to $(-6.4 \%$ $\pm 6.1 \%$ in) the border zone. Mean shear strain in the radial-longitudinal plane (Figure E5, C) decreases monotonically with distance from the base from a maximum positive value (of $2.5 \% \pm 7.4 \%$ ) near the base to a maximum negative value (of $4.7 \% \pm 5.7 \%$ ) in the border zone. Similarly, mean shear strain in the radial-circumferential plane (Figure E5, D) decreases monotonically with distance from the base from a maximum positive value (of $1.2 \% \pm$ $4.7 \%$ ) near the base to a maximum negative value (of $-0.7 \% \pm 3.7 \%$ ) in the border zone. Mean shear strain in the circumferential-longitudinal plane (Figure E5, E) was negative and relatively constant between $(-0.8 \% \pm 4.0 \%$ at $)$ the base and $(-0.9 \% \pm 5.7 \%$ in) the border zone, reaching an extreme value (of $-2.0 \% \pm 3.6 \%$ ) at the equator. The radial strain component is not presented in Figure E5 because it is not measured accurately with current tagged MRI methodology (see Discussion).

The repeated-measures analysis (see Methods: Statistical Analysis) was positive with respect to end-systolic circumferential and longitudinal strain components $(P<$ .0001 in each case). Figure 2 shows the effect of aneurysm plication on these 2 strain components. Figure 2, A, shows that circumferential shortening progressively increases from before plication to 2 weeks after plication to 6 weeks after plication toward the border zone. Figure 2 $B$, shows that longitudinal shortening is decreased at 2 weeks after plication but then returns to baseline at 6 weeks after plication. Figure 2, $C$ and $D$, shows the effect of aneurysm plication on circumferential and longitudinal systolic shortening when plotted against quadrant. The effect on circumferential shortening is most pronounced in the septum and anterior wall. Once again the biggest change is from 2 to 6 weeks after plication. The effect on longitudinal shortening is more diffuse, and once again there is a decrease at 2 weeks but a return to baseline (and slight improvement at the border zone) at 6 weeks after plication.

Preplication and 2- and 6-week postplication regional 3-dimensional midwall strain between end-diastole and endsystole are given in Tables 1 and 2. These data are presented at the centers of 4 different circumferential quadrants (posterior, lateral, anterior, and septal) in 4 different longitudinal slices (1, 2, 3, and $4 \mathrm{~cm}$ below the base). They can be used with our finite element method to determine myocardial contractility and stress in remote noninfarcted LV regions after aneurysm plication. 

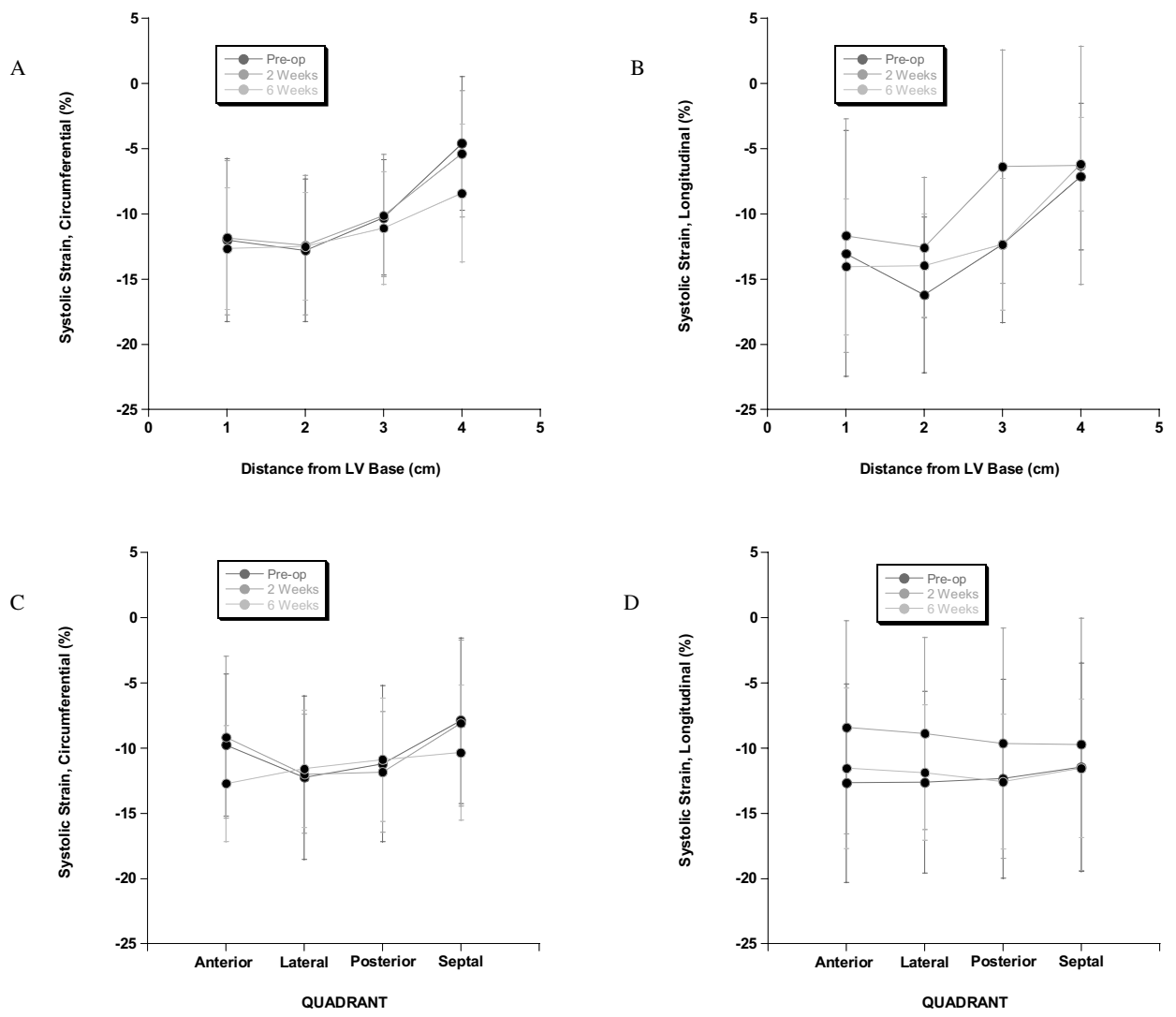

Figure 2. Effects of aneurysm plication on selected end-systolic strain tensor components. A, Circumferential strain versus distance from LV base. B, Longitudinal strain versus distance from LV base. C, Circumferential strain versus quadrant. D, Longitudinal strain versus quadrant.

\section{Discussion}

The primary finding of this 3-dimensional MRI tagging study is that repair of LV aneurysm significantly increases systolic circumferential shortening at the border zone in sheep. Longitudinal shortening is decreased at 2 weeks after plication but then returns to baseline at 6 weeks after plication. The effect on circumferential shortening is most pronounced in the septum and anterior wall. Moreover, the present study (together with our previous study ${ }^{9}$ of myocyte orientation using MR diffusion tensor imaging) provides the most complete set of data to date for creating and validating mathematical models for the mechanics of the infarcted left ventricle before and after aneurysm repair.

We are studying a variety of surgical ventricular remodeling operations including linear repair and patch aneurysmorrhaphy. Despite the strong clinical trend away from linear repair of LV aneurysm, it is not clear that a choice for patch aneurysmorrhaphy is correct. For instance, we have studied the effect of both linear repair ${ }^{1}$ and patch plasty ${ }^{10}$ on LV function. In brief, although the Starling relationship shifted downward immediately after plication ${ }^{1}$ and the slope of the Starling relationship was slightly greater (no significant difference) 2 weeks after patch plasty, ${ }^{10}$ in neither case was the Starling relationship changed at 6 weeks. We, therefore, think that the study of linear repair has merit. We studied linear repair (plication) first because it can be done without the use of cardiopulmonary bypass. We assume that the effect of aneurysm resection and linear closure on end-systolic 3-dimensional strain would be the same as that of aneurysm plication.

\section{Effect on Regional Strain}

Surgical volume reduction should be associated with a decrease in the force or stress that the ventricular muscle fibers must develop to generate the preoperative end-systolic pressure or afterload. Using the geometric model described above and assuming end-systolic pressure is not affected by the operation, an analysis based on statistics suggests that aneurysm plication decreases average circumferential wall stress by $24.6 \%{ }^{11}$ This could explain why aneurysm plication significantly increases regional circumferential shortening. 
TABLE 1. Regional circumferential strain (\%Ecc) between end-diastole and end-systole

\begin{tabular}{|c|c|c|c|}
\hline Region & $\begin{array}{c}\text { Before } \\
\text { plication }\end{array}$ & $\begin{array}{c}\text { Two weeks } \\
\text { after } \\
\text { plication }\end{array}$ & $\begin{array}{l}\text { Six weeks } \\
\text { after plication }\end{array}$ \\
\hline \multicolumn{4}{|c|}{$1 \mathrm{~cm}$ below base } \\
\hline Anterior & $-12.8 \pm 3.8$ & $-12.4 \pm 6.3$ & $-14.4 \pm 4.4^{*}$ \\
\hline Lateral & $-15.1 \pm 4.0$ & $-14.3 \pm 4.1$ & $-12.0 \pm 4.7^{*} \dagger$ \\
\hline Posterior & $-13.1 \pm 6.5$ & $-12.5 \pm 4.7$ & $-12.2 \pm 4.3$ \\
\hline Septal & $-9.1 \pm 7.3$ & $-9.7 \pm 6.5$ & $-12.0 \pm 4.9^{*} \dagger$ \\
\hline \multicolumn{4}{|c|}{$2 \mathrm{~cm}$ below base (equator) } \\
\hline Anterior & $-12.3 \pm 4.1$ & $-11.0 \pm 5.3$ & $-13.0 \pm 3.0 \dagger$ \\
\hline Lateral & $-15.8 \pm 4.3$ & $-14.8 \pm 3.6$ & $-11.9 \pm 3.8^{*} \dagger$ \\
\hline Posterior & $-14.6 \pm 4.9$ & $-14.5 \pm 3.2$ & $-12.5 \pm 4.3^{*} \dagger$ \\
\hline Septal & $-10.3 \pm 6.1$ & $-10.7 \pm 6.4$ & $-12.4 \pm 4.1^{*}$ \\
\hline \multicolumn{4}{|c|}{$3 \mathrm{~cm}$ below base } \\
\hline Anterior & $-9.7 \pm 4.0$ & $-8.8 \pm 4.6$ & $-11.9 \pm 4.3^{*} \dagger$ \\
\hline Lateral & $-12.1 \pm 5.2$ & $-11.8 \pm 3.0$ & $-13.0 \pm 3.7$ \\
\hline Posterior & $-11.8 \pm 3.2$ & $-12.5 \pm 3.6$ & $-10.6 \pm 3.6 \dagger$ \\
\hline Septal & $-8.7 \pm 4.6$ & $-8.5 \pm 5.2$ & $-9.8 \pm 4.8$ \\
\hline \multicolumn{4}{|c|}{$4 \mathrm{~cm}$ below base (border zone) } \\
\hline Anterior & $-4.3 \pm 5.2$ & $-4.6 \pm 5.5$ & $-11.3 \pm 4.4^{*} \dagger$ \\
\hline Lateral & $-6.0 \pm 6.2$ & $-7.1 \pm 2.7$ & $-8.9 \pm 5.0^{*} \dagger$ \\
\hline Posterior & $-5.3 \pm 4.3$ & $-7.8 \pm 4.1^{*}$ & $-7.7 \pm 5.4^{*}$ \\
\hline Septal & $-3.5 \pm 4.9$ & $-3.3 \pm 4.6$ & $-6.5 \pm 5.1^{*} \dagger$ \\
\hline
\end{tabular}

Values are mean \pm SD. $* P<.05,2$ - and 6-week plication versus before plication. $\dagger P<.05$, 2-week plication versus 6 -week plication.

Regional systolic strain is also determined by myocyte contractility. If the ability of the muscle fibers in an LV region to develop force or stress is increased and the load on these myofibers remains the same or decreases, then the amount of myofiber shortening will increase. Unfortunately, the direct measurement of local forces or stresses in the intact heart wall has been unreliable. ${ }^{12}$ An alternative approach to determine ventricular wall stress is mathematical modeling based on the conservation laws of continuum mechanics. ${ }^{13}$ In a previous study, ${ }^{14}$ we created a realistic mathematical model of the 3-dimensional ovine left ventricle with an anteroapical aneurysm from multiple short-axis and long-axis MR images at the beginning of diastolic filling, and we used circumferential strain measured at endisovolumic systole by Moulton and coworkers ${ }^{15}$ in the anterior and posterior border zone regions to determine myocardial contractility and stress in these regions. Our mathematical (finite element) model suggests that the significant increase in regional circumferential shortening after aneurysm plication is primarily the result of a decrease in load on the myofibers rather than an increase in regional myocardial contractility.

On the other hand, reduced contractility may have caused the reduced longitudinal strain seen 2 weeks after plication. High diastolic stress, which causes reduced global contractility ${ }^{16}$ and eccentric hypertrophy, ${ }^{17}$ may occur after surgi-
TABLE 2. Regional longitudinal strain (\%Ell) between end-diastole and end-systole

\begin{tabular}{lccc}
\hline Region & $\begin{array}{c}\text { Before } \\
\text { plication }\end{array}$ & $\begin{array}{c}\text { Two weeks } \\
\text { after plication }\end{array}$ & $\begin{array}{c}\text { Six weeks } \\
\text { after plication }\end{array}$ \\
\hline 1 cm below base & & & \\
Anterior & $-16.9 \pm 5.1$ & $-14.4 \pm 8.6$ & $-17.2 \pm 5.1 \dagger$ \\
Lateral & $-11.8 \pm 10.4$ & $-12.3 \pm 6.8$ & $-14.2 \pm 6.7$ \\
Posterior & $-11.4 \pm 10.0$ & $-9.2 \pm 9.5$ & $-11.0 \pm 4.4$ \\
Septal S & $-12.0 \pm 10.4$ & $-11.1 \pm 9.3$ & $-14.0 \pm 3.5 \dagger$ \\
2 cm below base (equator) & & \\
Anterior & $-16.3 \pm 4.7$ & $-10.1 \pm 5.8^{*}$ & $-12.1 \pm 4.5^{*} \dagger$ \\
Lateral & $-16.4 \pm 5.6$ & $-9.9 \pm 5.0^{*}$ & $-12.5 \pm 2.2^{*} \dagger$ \\
Posterior & $-16.5 \pm 8.2$ & $-14.0 \pm 4.4^{*}$ & $-16.0 \pm 2.9 \dagger$ \\
Septal & $-15.8 \pm 5.1$ & $-14.7 \pm 4.6$ & $-14.5 \pm 3.9$ \\
3 cm below base & & & \\
Anterior & $-10.2 \pm 8.4$ & $-3.5 \pm 5.2^{*}$ & $-9.2 \pm 5.4 \dagger$ \\
Lateral & $-14.0 \pm 2.4$ & $-6.3 \pm 7.3^{*}$ & $-13.5 \pm 3.7 \dagger$ \\
Posterior & $-14.3 \pm 2.4$ & $-9.5 \pm 8.4^{*}$ & $-16.1 \pm 2.7^{*} \dagger$ \\
Septal & $-11.6 \pm 6.4$ & $-6.2 \pm 11.4^{*}$ & $-11.3 \pm 4.9 \dagger$ \\
4 cm below base (border zone) & & \\
Anterior & $-7.3 \pm 7.0$ & $-5.6 \pm 8.0$ & $-7.0 \pm 4.5$ \\
Lateral & $-8.2 \pm 4.2$ & $-6.9 \pm 8.5$ & $-6.3 \pm 2.8^{*}$ \\
Posterior & $-7.0 \pm 3.6$ & $-5.8 \pm 10.1$ & $-6.2 \pm 2.9$ \\
Septal & $-6.5 \pm 6.3$ & $-6.9 \pm 9.6$ & $-5.4 \pm 3.6$
\end{tabular}

Values are mean \pm SD. $* P<.05,2$ - and 6 -week plication versus before plication. $\dagger P<.05$, 2-week plication versus 6 -week plication.

cal remodeling. For instance, Savage and coworkers ${ }^{2}$ have suggested that aneurysm plication leads to increased diastolic stress in the longitudinal direction. Although we have previously shown that residual stress has no effect on Starling's law after partial ventriculectomy, ${ }^{18}$ it is possible that aneurysm plication causes an increase in longitudinal diastolic stress of sufficient magnitude both to reduce contractility and to a stimulate postoperative remodeling (see Redilation below).

\section{Interaction With Global Function}

Unfortunately, this improvement in regional systolic function is not necessarily associated with an improvement in global ventricular function. Although ejection fraction increased significantly 2 weeks after aneurysm plication, stroke volume was essentially unchanged at 2 and 6 weeks postoperatively compared with the preplication value. Thus, the significant improvement in ejection fraction after aneurysm plication is due entirely to the surgical (end-diastolic) volume reduction. Apparently, this substantial reduction in end-diastolic volume prevented the significant increase in circumferential and longitudinal shortening in several LV regions after aneurysm plication from resulting in an improvement in stroke volume. If we were to idealize LV wall geometry as a hemispheric shell that is $10 \mathrm{~mm}$ thick at end-diastole and is made of an incompressible material, then a shell with an end-diastolic chamber volume of $64.2 \mathrm{~mL}$ 
would require $7.5 \%$ midwall circumferential shortening to achieve a $20.1-\mathrm{mL}$ stroke volume, whereas a shell with a much larger 120.1-mL end-diastolic chamber volume would require only $3.6 \%$ midwall circumferential shortening to achieve a comparable $17.7-\mathrm{mL}$ stroke volume. These numerical values are consistent with those in Tables E1 and 1 for sham versus plication end-diastolic volume, stroke volume, and midwall circumferential shortening at 2 weeks postoperatively. Of course, this extremely simple geometric model does not account for apex-to-base or circumferential variations in shortening.

\section{Redilation}

There was a trend toward redilation, but neither end-diastolic volume nor end-systolic volume returned to preplication values 6 weeks after plication, as observed previously by Ratcliffe and coworkers. ${ }^{1}$ In their previous study, absolute LV volume was measured by long-axis transdiaphragmatic echocardiography, and relative changes in LV volume were measured with a conductance catheter. We consider the MRI-based methodology used in the present study to be the more accurate method for measuring LV volume. In any case, the abrupt increase in circumferential and longitudinal shortening and presumed decrease in LV wall stress after aneurysm plication does not appear to be sufficient to prevent redilation.

Eccentric hypertrophy of the remote myocardium is thought to be caused by increased diastolic stress. Maybe we have not reduced diastolic stress enough. We think that nonischemic infarct extension is driven by high systolic stress and strain. Maybe we have not removed this stimulus. For instance, systolic longitudinal shortening increases at 2 weeks. Also, $4 \mathrm{~cm}$ may not be far enough down the left ventricle to determine the effect on all parts of the border zone (ie, lateral and posterior walls) since the plication is not axisymmetric.

\section{Limitations}

Clearly, the major limitation of the present study is the relatively small numbers of animals that were subjected to the entire protocol. The major difficulty and cause of lost tagged MR data is with ECG-gating due to interference from the strong magnetic field.

End-systolic radial strain tends to be more variable than circumferential strain in tagged MR images. ${ }^{19}$ One factor in radial strain variablility is that tagging with either parallel lines or rectangular grids results in relatively sparse sampling of myocardial motion in the radial direction. For example, a 10-mm-thick myocardium with a tag spacing of $8 \mathrm{~mm}$ yields only one or two tag lines in the radial direction, which makes the resulting measurement of radial strain sensitive to noise in the tag line position measurements and highly influenced by the deformation model.
Another source of variability in both radial and longitudinal strain is the difficulty of defining the radial and longitudinal directions on the curved LV wall, particularly at the apex.

Another limitation of the present study is the limited spatial and temporal resolution associated with our MR image acquisition. In several of our experiments, we acquired tagged short-axis images that were separated by 1 $\mathrm{cm}$. Since the long-axis length of plicated left ventricles was significantly less than that of the other left ventricles, strain comparisons could be made only in the short-axis slices 1 to $4 \mathrm{~cm}$ below the valves. Moreover, the border zone in the anterior LV wall was contained within the latter slice, but the other border zone regions were located below it. Thus, it is not entirely accurate to label all LV regions in the short-axis slice $4 \mathrm{~cm}$ below the valves as border zone regions. We acquired tagged MR images every 40 milliseconds between end-diastole and end-systole. This temporal resolution was not sufficient to rigorously study strain during isovolumic systole and thus prevented us from confirming the measurements of Moulton and coworkers. ${ }^{15}$

No baseline imaging (ie, before infarction) was performed during the present study. This would have allowed comparison of regional differences in contractility to be assessed and would have permitted therapy to be compared with normal. Such analysis would better elucidate the effect of the remodeling procedure. Since the effect of the anteroapical infarct in sheep on regional 2-dimensional (circumferential) myocardial strain has already been measured, ${ }^{20}$ however, we did not think that preinfarct and immediately postinfarct data collection was critical.

\section{Conclusions and Future Directions}

Repair of LV aneurysm significantly increases systolic circumferential shortening at the border zone in sheep. Tables E1, 1, and 2 can be used with our finite element method to determine myocardial contractility and stress in remote noninfarcted LV regions after aneurysm plication. Moreover, the same methodology presented in the article can be applied to other techniques (eg, circular patch plasty) for repair of LV aneurysm.

We thank Dr Charles McCulloch, Professor and Head, Division of Biostatistics, University of California San Francisco, for his guidance on the statistical analysis. We thank Dr J. M. Guccione, Sr, for his help in the construction of the plastic container used in this study.

\section{References}

1. Ratcliffe MB, Wallace AW, Salahieh A, Hong J, Ruch S, Hall TS. Ventricular volume, chamber stiffness, and function after anteroapical aneurysm plication in the sheep. J Thorac Cardiovasc Surg. 2000;119: $115-24$.

2. Savage EB, Downing SW, Ratcliffe MB, Fallert M, Gupta KB, Tyson GS, et al. Repair of left ventricular aneurysm: changes in ventricular mechanics, hemodynamics, and oxygen consumption. $J$ Thorac Cardiovasc Surg. 1992;104:752-62. 
3. Kramer CM, Magovern JA, Rogers WJ, Vido D, Savage EB. Reverse remodeling and improved regional function after repair of left ventricular aneurysm. J Thorac Cardiovasc Surg. 2002;123:617-20.

4. Markovitz LJ, Savage EB, Ratcliffe MB, Bavaria JE, Kreiner G, Iozzo $\mathrm{RV}$, et al. Large animal model of left ventricular aneurysm. Ann Thorac Surg. 1989;48:838-45.

5. Guttman MA, Zerhouni EA, McVeigh ER. Analysis and visualization of cardiac function from MR images. IEEE Comp Graph Appl. 1997; 17:30-8.

6. Ozturk C, McVeigh ER. Four-dimensional B-spline based motion analysis of tagged MR images: introduction and in vivo validation. Phys Med Biol. 2000;45:1683-702.

7. Krueger C, Tian L. A comparison of the general linear mixed model and repeated measures ANOVA using a dataset with multiple missing data points. Biol Res Nurs. 2004;6(2):151-7.

8. Wooding W. Planning pharmaceutical clinical trials: basic statistical principals. Probability and mathematical statistics. New York: John Wiley and Sons; 1994. p 34-6.

9. Walker JC, Guccione JM, Jiang Y, Zhang P, Wallace AW, Hsu EW, et al. Helical myofiber orientation after myocardial infarction and left ventricular surgical restoration in sheep. J Thorac Cardiovasc Surg. 2005; 129:382-90.

10. Zhang P, Guccione JM, Nicholas SI, Walker JC, Crawford PC, Shamal A, et al. Left ventricular volume and function after endoventricular patch plasty for dyskinetic anteroapical left ventricular aneurysm in sheep. J Thorac Cardiovasc Surg. 2005;130:1032-8.

11. Fung YC. Biodynanics: circulation. New York: Springer-Verlag; 1996.

12. Huisman RM, Elzinga G, Westerhof N, Sipkema P. Measurement of left ventricular wall stress. Cardiovasc Res. 1980;14:142-53.
13. Bergel DA, Hunter PH. The mechanics of the heart. In: Quantitative cardiovascular studies. Hwang NHC, Gross DR, Patel DJ, editors. Baltimore: University Park Press; 1979.

14. Guccione JM, Moonly SM, Moustakidis P, Costa KD, Moulton MJ, Ratcliffe MB, et al. Mechanism underlying mechanical dysfunction in the border zone of left ventricular aneurysm: a finite element model study. Ann Thorac Surg. 2001;71:654-62.

15. Moulton MJ, Downing SW, Creswell LL, Fishman DS, Amsterdam DM, Szabo BA, et al. Mechanical dysfunction in the border zone of an ovine model of left ventricular aneurysm. Ann Thorac Surg. 1995;60: 986-98.

16. Downing SW, Savage EB, Streicher JS, Bogen DK, Tyson GS, Edmunds LH Jr. The stretched ventricle: myocardial creep and contractile dysfunction after acute nonischemic ventricular distention. J Thorac Cardiovasc Surg. 1992;104:996-1005.

17. Grossman W, Jones D, McLaurin LP. Wall stress and patterns of hypertrophy in the human left ventricle. J Clin Invest. 1975;56:5664.

18. Guccione JM, Moonly SM, Wallace AW, Ratcliffe MBL. Residual stress produced by ventricular volume reduction surgery has little effect on ventricular function and mechanics: a finite element model study. J Thorac Cardiovasc Surg. 2001;122:592-9.

19. Denney TS Jr, Gerber BL, Yan L. Unsupervised reconstruction of a three-dimensional left ventricular strain from parallel tagged cardiac images. Magn Reson Med. 2003;49:743-54.

20. Kramer CM, Lima JA, Reichek N, Ferrari VA, Llaneras MR, Palmon LC, et al. Regional differences in function within noninfarcted myocardium during left ventricular remodeling. Circulation. 1993;88: $1279-88$

Access to The Journal of Thoracic and Cardiovascular Surgery Online is reserved for print subscribers!

Full-text access to The Journal of Thoracic and Cardiovascular Surgery Online is available for all print subscribers. To activate your individual online subscription, please visit The Journal of Thoracic and Cardiovascular Surgery Online, point your browser to http://www.mosby.com/itcvs, follow the prompts to activate your online access, and follow the instructions. To activate your account, you will need your subscriber account number, which you can find on your mailing label (note: the number of digits in your subscriber account number varies from 6 to 10). See the example below in which the subscriber account number has been circled:

\section{Sample mailing label}

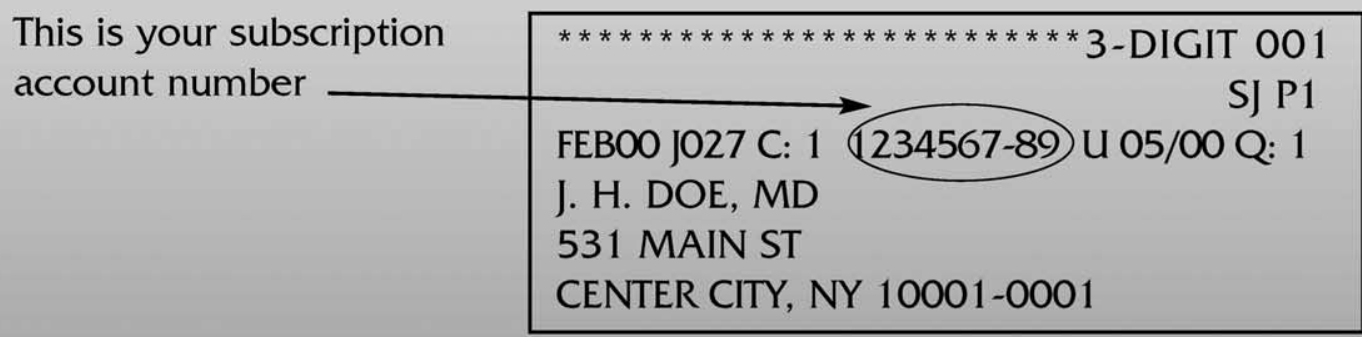

Personal subscriptions to The Journal of Thoracic and Cardiovascular Surgery Online are for individual use only and may not be transferred. Use of The Journal of Thoracic and Cardiovascular Surgery Online is subject to agreement to the terms and conditions as indicated online. 
A

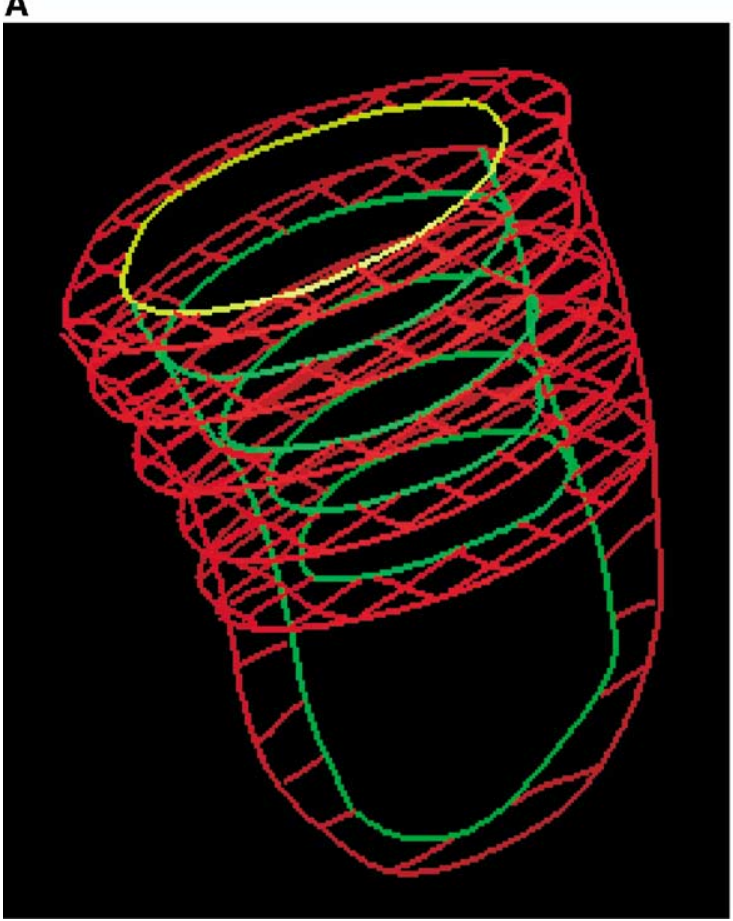

B

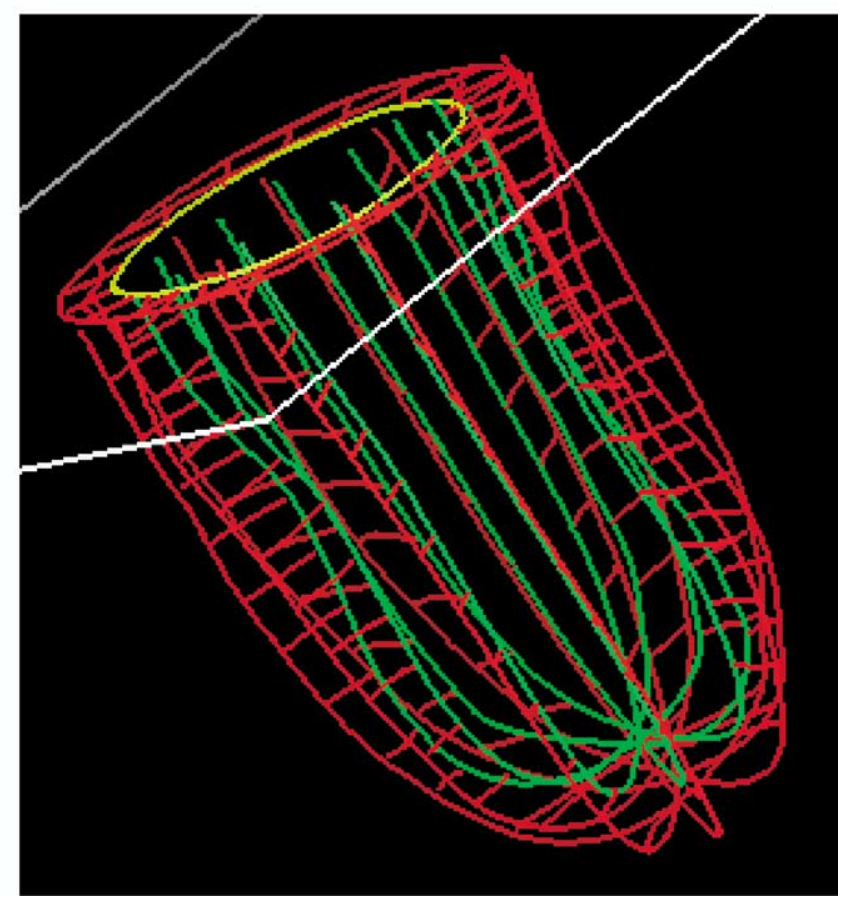

Figure E1. End-diastolic 3-dimensional tagged MRI data set. A, Five short-axis (separated by $1 \mathrm{~cm}$ ) and one long-axis image planes/slices. B, Six long-axis (equally separated by $30^{\circ}$ around the LV circumference) and one short-axis image slices. The endocardial contours are highlighted in green and yellow.

A

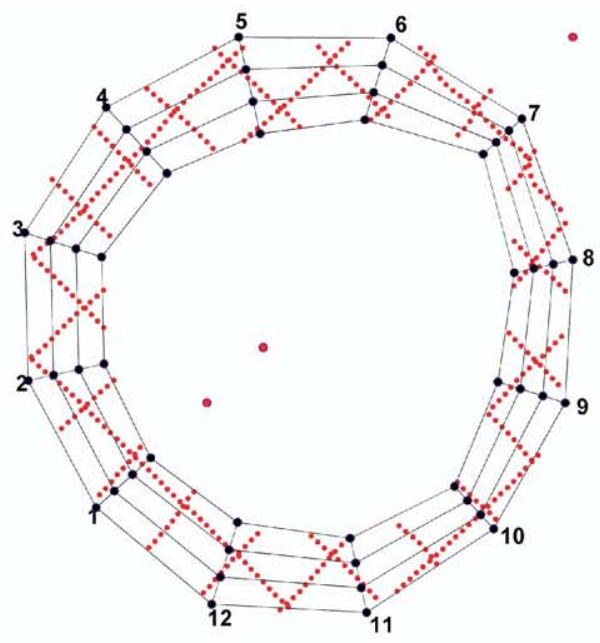

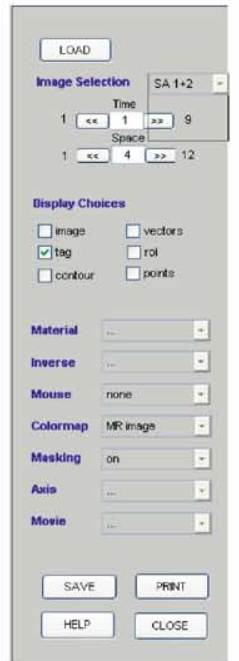

B

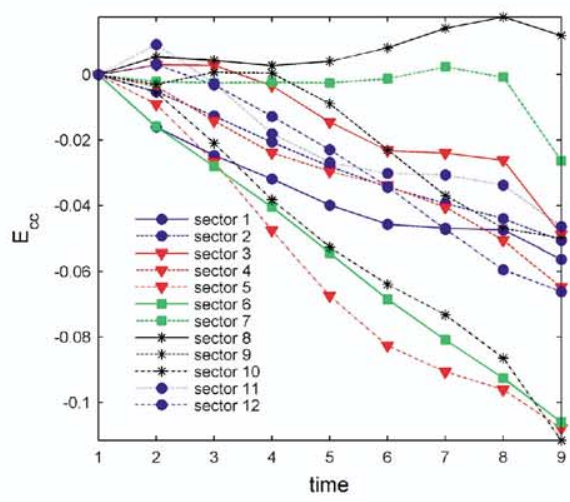

Figure E2. A, Time series throughout systole of the 3-dimensional Green strain component in the local circumferential direction (Ecc) at the midwall (shell 2) of 12 different sectors in a short-axis plane/slice that was near the border zone at end-diastole (time 1) of a sheep before its anteroapical LV aneurysm was plicated. B, Sectors $2,5,8$, and 11 correspond to the central/middle portions of the posterior LV wall, lateral LV wall, anterior LV wall, and interventricular septum, respectively. 
A

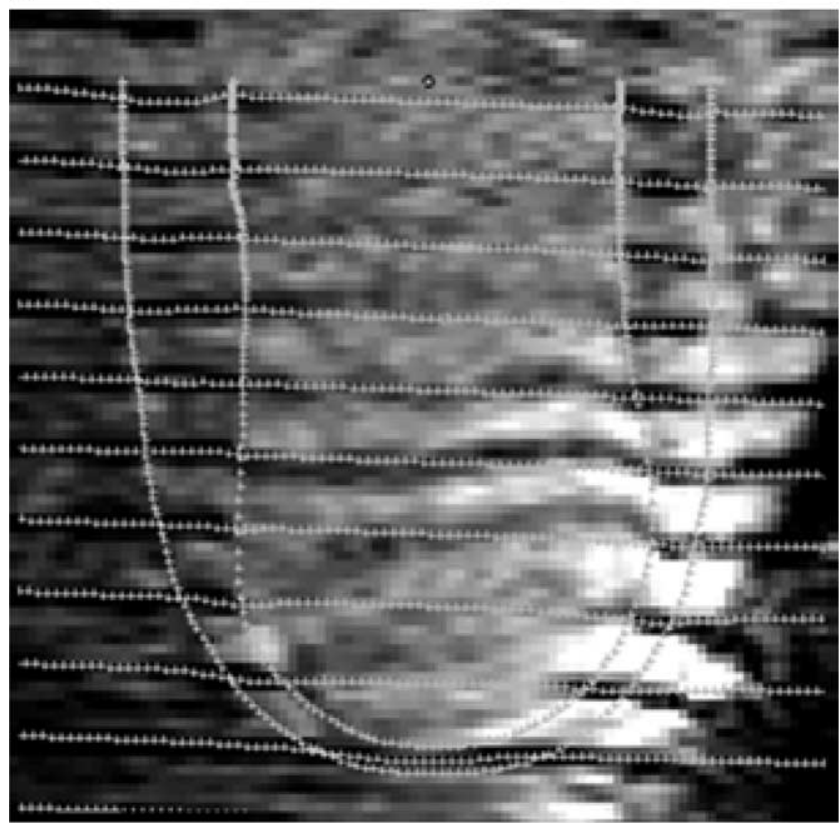

B

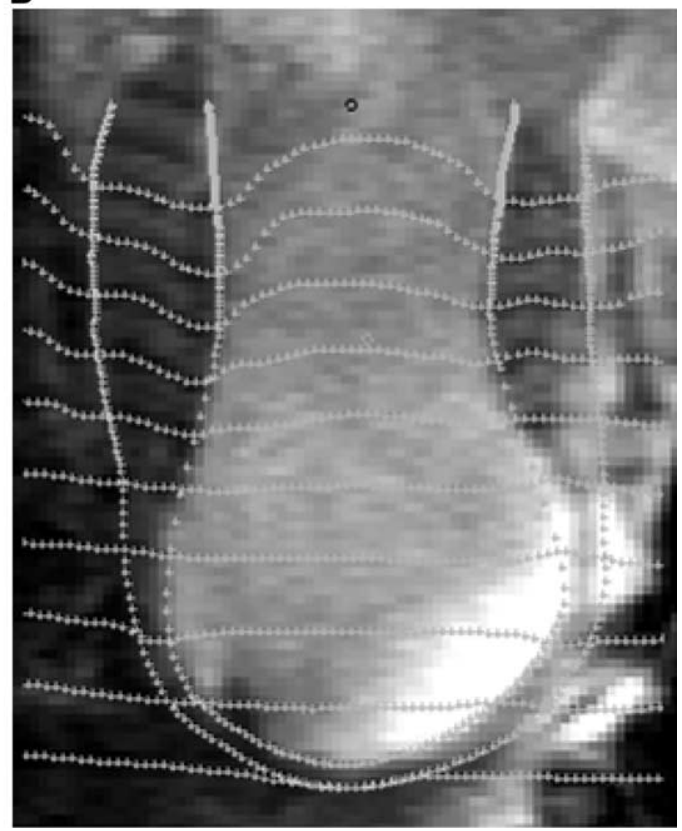

Figure E3. End-diastolic (A) and end-systolic (B) long-axis tagged MR images of sheep heart with LV aneurysm. Note the significant through-plane motion, which varies monotonically from approximately the tag spacing $(8 \mathrm{~mm})$ near the LV base to zero near the apex.

TABLE E1. Repeated measures of baseline values, pressures, and volumes

\begin{tabular}{lcll}
\hline & Before plication & $\begin{array}{c}\text { Two weeks } \\
\text { after plication }\end{array}$ & $\begin{array}{c}\text { Six weeks } \\
\text { after plication }\end{array}$ \\
\hline Weight $(\mathrm{kg})$ & $34.6 \pm 2.0$ & $30.7 \pm 2.1$ & $31.3 \pm 2.4$ \\
LVP at ED $(\mathrm{mm} \mathrm{Hg})$ & $16.7 \pm 8.3$ & $18.1 \pm 13.0$ & $17.0 \pm 12.1$ \\
LVP at ES $(\mathrm{mm} \mathrm{Hg})$ & $90.5 \pm 21.5$ & $91.9 \pm 18.3$ & $99.3 \pm 19.7$ \\
EDV $(\mathrm{mL})$ & $92.8 \pm 17.8$ & $64.2 \pm 13.2^{*}$ & $72.6 \pm 17.2$ \\
ESV $(\mathrm{mL})$ & $71.2 \pm 13.7$ & $44.1 \pm 11.8^{*}$ & $51.2 \pm 11.6^{*}$ \\
SV $(\mathrm{mL})$ & $21.6 \pm 8.9$ & $20.2 \pm 4.8$ & $21.5 \pm 8.3$ \\
EF $(\%)$ & $23.0 \pm 7.6$ & $32.0 \pm 7.2^{*}$ & $28.9 \pm 7.7$ \\
\hline
\end{tabular}

Values are mean $\pm \mathrm{SD}$. $L V P$, Left ventricular pressure; $E D$, end-diastole; $E S$, end-systole; $E D V$, end-diastolic volume; $E S V$, end-systolic volume; $S V$, stoke volume; $E F$, ejection fraction. $* P<.05,2$ - and 6 -week plication versus before plication. $† P<.05$, 2-week plication versus 6 -week plication.

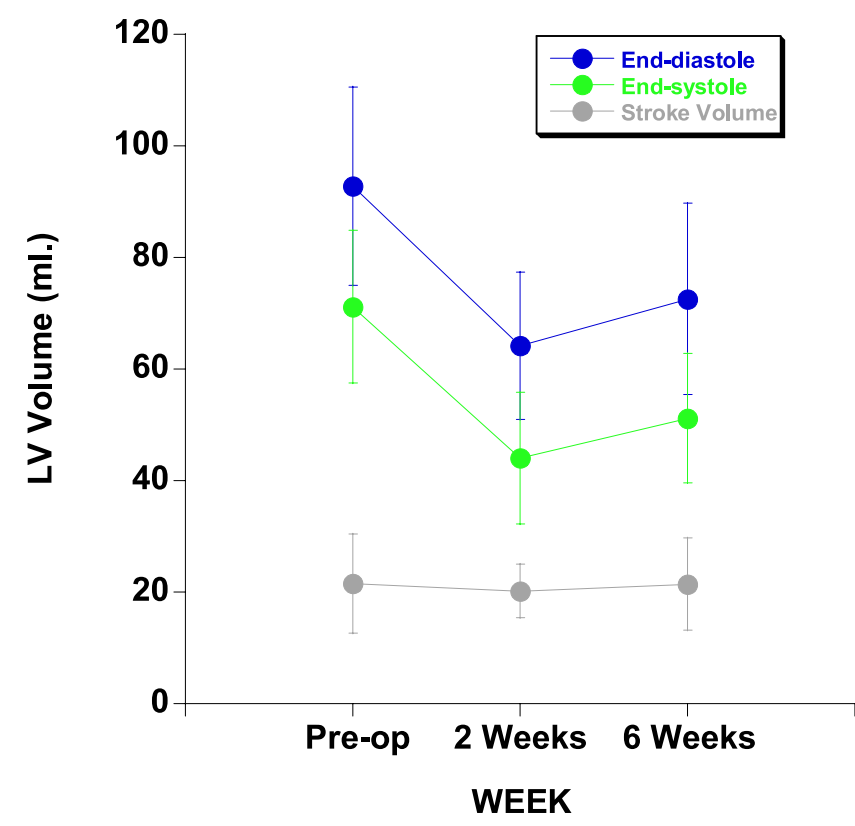

Figure E4. Effect of aneurysm plication on LV volume. 

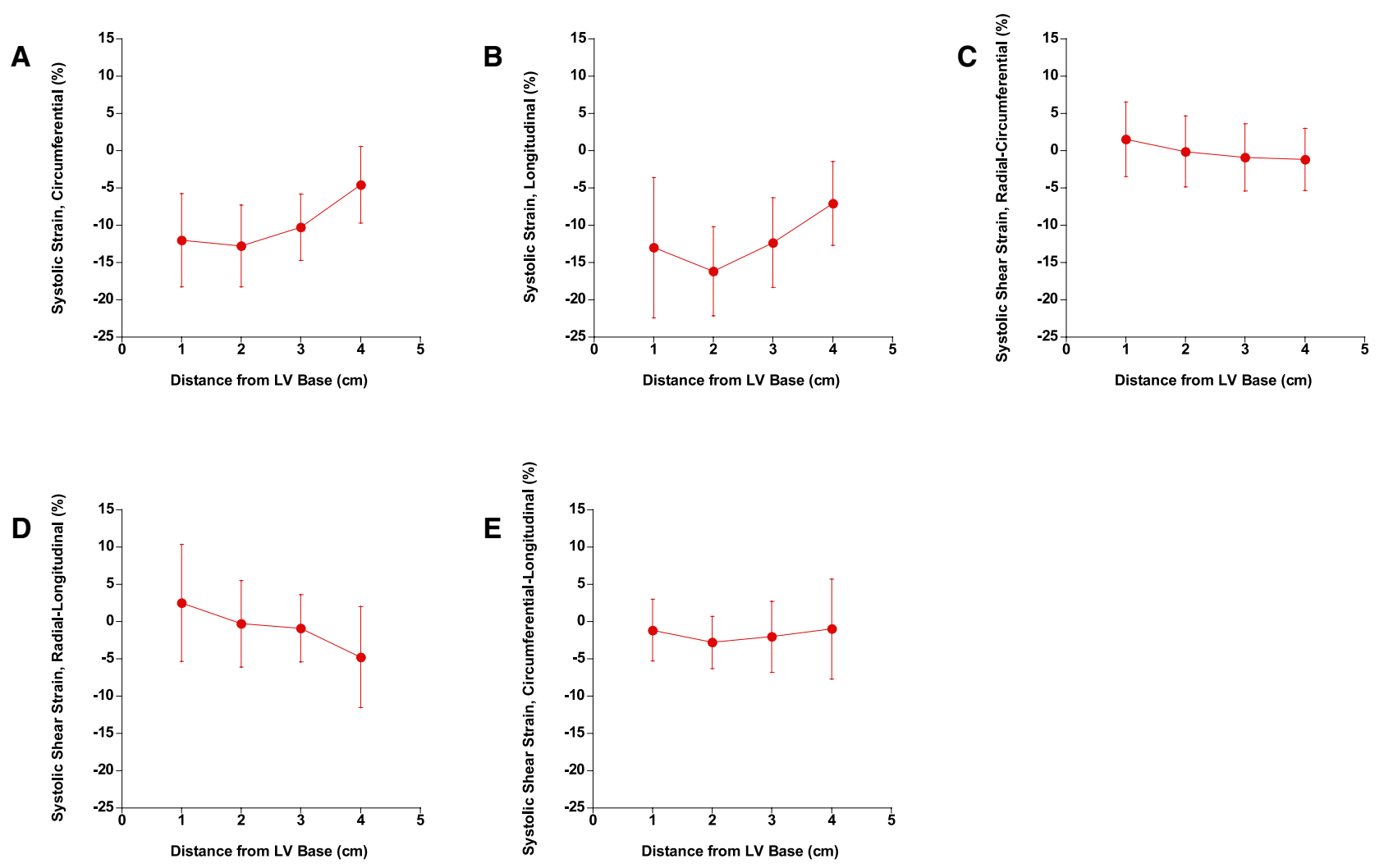

Figure E5. Longitudinal variation in selected end-systolic strain tensor components before aneurysm plication. A, Circumferential strain. B, Longitudinal strain. C, Shear strain in the radial-circumferential plane. D, Shear strain in the radial-Iongitudinal plane. E, Shear strain in the circumferential-longitudinal plane. These plots represent aggregate absolute baseline strains versus distance from base. Error bars indicate 1 standard deviation. 